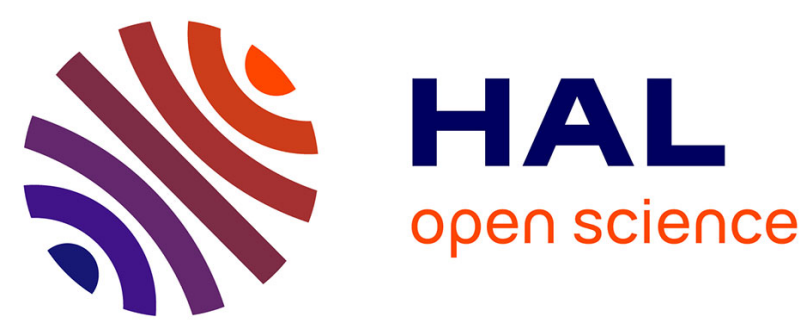

\title{
Causes of fever in pregnant women with acute undifferentiated fever: a prospective multicentric study
} Caroline Charlier, Elodie Perrodeau, Camille Levallois, Thierry Cachina, Marc

Dommergues, Laurent J. Salomon, Elie Azria, François Goffinet, Philippe Ravaud, Marc Lecuit

\section{To cite this version:}

Caroline Charlier, Elodie Perrodeau, Camille Levallois, Thierry Cachina, Marc Dommergues, et al.. Causes of fever in pregnant women with acute undifferentiated fever: a prospective multicentric study. European Journal of Clinical Microbiology and Infectious Diseases, 2020, 39 (5), pp.999-1002. 10.1007/s10096-019-03809-3 . pasteur-02979326

\section{HAL Id: pasteur-02979326 \\ https://hal-pasteur.archives-ouvertes.fr/pasteur-02979326}

Submitted on 27 Oct 2020

HAL is a multi-disciplinary open access archive for the deposit and dissemination of scientific research documents, whether they are published or not. The documents may come from teaching and research institutions in France or abroad, or from public or private research centers.
L'archive ouverte pluridisciplinaire HAL, est destinée au dépôt et à la diffusion de documents scientifiques de niveau recherche, publiés ou non, émanant des établissements d'enseignement et de recherche français ou étrangers, des laboratoires publics ou privés. 
3

4

\section{Causes of fever in pregnant women with acute undifferentiated fever:}

\section{a prospective multicentric study}

${ }^{1}$ Institut Pasteur, Biology of Infection Unit, Paris, France

${ }^{2}$ Inserm U1117, Paris, France

${ }^{3}$ Institut Pasteur, French National Reference Center and WHO Collaborating Center for Listeria, Paris-France

${ }^{4}$ Université de Paris, Hôpital Universitaire Necker-Enfants Malades, Division of Infectious Diseases and Tropical Medicine, Assistance Publique-Hôpitaux de Paris, Institut Imagine, Paris, France

${ }^{5}$ Centre of Research in Epidemiology and Statistics Sorbonne Paris Cité, METHODS Team, UMR 1153, Inserm, Université de Paris, Paris, France

${ }^{6}$ Pierre et Marie Curie University, Pitié Salpêtrière University Hospital, Assistance Publique-Hôpitaux de Paris, Paris, France

${ }^{7}$ Maternity Unit, Paris Saint Joseph Hospital, Université de Paris, Paris, France

${ }^{8}$ Université de Paris, Hôpital Cochin Port Royal, Port Royal Maternity, Department of Obstetrics, Cochin Port Royal Hospital, Assistance Publique-Hôpitaux de Paris, Paris, France

Key words: undifferentiated fever, listeriosis, pregnancy, pyelonephritis, influenza

Running title: etiologies for fever in pregnancy

Word count: 930 words

\section{Correspondence to:}

Caroline Charlier, caroline.charlier@pasteur.fr

Marc Lecuit, marc.lecuit@pasteur.fr

Unité de Biologie des Infections, Institut Pasteur, Inserm U1117, 28 rue du Dr Roux, 75015 Paris, France Phone: +33140613420

Fax: +33140613421 

undifferentiated fever in pregnant women, requiring careful repeated evaluation.

\section{Abstract} pregnant women who received preemptive listeriosis treatment. and final diagnosis were collected. influenza or TORCH infections.

Purpose - The etiologies of undifferentiated fever in pregnant women have not been studied thoroughly. Because of its non-specific presentation but severe prognosis, listeriosis is often suspected in this setting, but in most cases not confirmed. We studied the causes of undifferentiated fever in

Methods - We conducted from November $1^{\text {st }} 2011$ to June $30^{\text {th }} 2013$ a prospective multicentric observational cohort study of pregnant women referred to obstetrical wards with undifferentiated fever and who received listeriosis preemptive treatment. Clinical and biological features, treatment, outcome

Results — We enrolled 103 febrile pregnant women. A cause was identifiedin 77/103 (75\%): viral infection in 52/103 (50\%, influenza in $21(20 \%))$, bacterial infection in $22(21 \%$, including 16 pyelonephritis (16\%) and 3 pneumonias (3\%)), TORCH infection in $3(3 \%$, varicella, toxoplasmosis and cytomegalovirus primo infections). Viral infections collected during influenza outbreaks (December-March) accounted for 43/57 (75\%) cases. Two fetal losses were reported in the context of febrile pneumonia. Final diagnoses required adapting medical care in 46/77 (60\%) of cases, for bacterial,

Conclusions - A large array of benign to potentially severe infections manifest as acute 50 


\section{Introduction}

Undifferentiated fever, i.e. without organ-specific symptoms, is a challenging symptom that has not been thoroughly studied in pregnant women $[1,2]$. Initial evaluation of febrile pregnant women aims at (i) evaluating emergency (sepsis, intra-uterine infection, pyelonephritis, meningitis, malaria), (ii) identifying infections requiring interventions (pneumonia, sinusitis, TORCH infections, chickenpox), and (iii) identifying benign illnesses (viral gastro-enteritis or pharyngitis) [3]. In pregnant women, undifferentiated fever often leads to consider listeriosis, given its non-specific presentation and poor outcome (fetal loss, prematurity and neonatal infection) [4-7]. Recommendations favor empirical amoxicillin in this setting, especially after documented exposure [8,9] or during an outbreak $[10,11]$. However, as listeriosis is rare, with incidence of $10 / 10^{6}$ pregnant women [12], fever is in most cases not attributable to listeriosis. We prospectively enrolled pregnant women referred to the obstetrical ward for undifferentiated fever, and studied the causes of fever.

\section{Material and methods}

Study design and patients — The study took place from November 2011 to June 2013 in 4 Parisian tertiary maternity wards.

The MONALISA study is registered at Clinical.Trials.gov (NCT01520597). It is an ongoing prospective French observational study compiling all microbiologically-proven cases of listeriosis since 2009. The study also included from 2011 to 2013 a control cohort of patients with symptoms evocative of listeriosis, for whom this diagnosis was not confirmed [4]. Among these, we prospectively enrolled pregnant women referred for undifferentiated fever $\left(>37.7^{\circ} \mathrm{C}\right)$, leading to preemptive listeriosis treatment, according to French guidelines [13]. Data on past medical history, features at admission, results of repeated evaluations and tests, treatments, final diagnosis and outcome were collected.

Statistical analysis - Quantitative variables were described with the median and interquartile range $\left[25^{\text {th }}-75^{\text {th }}\right.$ percentile $]$. Mann-Whitney tests were used to compare quantitative variables. 
Cohort - 103 pregnant women were included (Table1). Median term was 32 weeks (interquartile range [28-36]). All patients reported the consumption of $\geq 1$ food at risk of listeriosis.

Biochemical results — Inflammatory markers were significantly higher in bacterial than in viral infections, with higher median leucocytes count $\left(10,435 / \mathrm{mm}^{3}[8,775-13,675]\right.$ vs. $8,000 / \mathrm{mm}^{3}[6,390-$ $10,250], \mathrm{p}=0.004)$, polymorphonuclear cells count $\left(9,615 / \mathrm{mm}^{3}[6,010-11,630]\right.$ vs. $5,925 / \mathrm{mm}^{3}[4,630-$ 8,260], $\mathrm{p}=0.004)$ and C-reactive protein (CRP) level (74 mg/L [49-122] vs. $40 \mathrm{mg} / \mathrm{L}$ [20-50], p=0.0001). Inflammatory markers in patients without final diagnosis were significantly higher than in viral infections (median leucocytes count $8,100 / \mathrm{mm} 3[6,400-10,550](\mathrm{p}=0.009)$, median polymorphonuclear cells count 8,990/mm3 [5,270-12,220] ( $\mathrm{p}=0.04)$ and median CRP level $49 \mathrm{mg} / \mathrm{L}$ [33-74] $(\mathrm{p}=0.01))$, but not different from patients with bacterial infections (data not shown). Twelve patients with RT-PCRconfirmed influenza $(12 / 21,57 \%)$ had CRP level $>20 \mathrm{mg} / \mathrm{L}$.

Microbiological results — Blood, urine and vaginal sample cultures were performed in all cases. Additional tests were performed according to local protocols or new clinical findings. No patient had Listeria positive culture or PCR results. 42 patients had microbiologically-confirmed infections: 21 had positive influenza RT-PCR on nasopharyngeal swabbing, 16 with pyelonephritis had positive urine culture. Other results included: varicella PCR on skin swabbing, enterovirus RT_PCR in cerebrospinal fluid, documentation of Salmonella sp. in stool culture, evidence for cytomegalovirus or toxoplasmosis seroconversion $(\mathrm{n}=1$, each).

Diagnoses - Altogether, a diagnosis was made in 77/103 cases (75\%) (Table 1). Diagnoses were confirmed microbiologically (see above), radiologically (chest X-ray for pneumonia) or clinically (repeated evaluations in dental abscesses and pharyngitis). Viral infections accounted for 52/103 (50\%) of cases, with seasonal variations: $43 / 57$ cases during the flu epidemic (December-March, 75\%, including 21 influenza), but only 9/46 (20\%) cases outside this timeframe $(\mathrm{p}<0.0001)$. In 26 patients $(26 / 103,25 \%)$, fever remained unexplained but resolved within 1-4 days under amoxicillin. 
Maternal treatment — All patients received anti-Listeria antibiotic treatment for a median of 7 days [6-

105 7]. Most patients with pyelonephritis required antibiotics changes: 10/16 with amoxicillin-resistant 106 pathogen were switched to $3^{\text {rd }}$ generation cephalosporins $(n=9)$ or amoxicillin-clavulanate $(n=1) ; 3$ 107 received aminoglycoside. Patients with RT-PCR-confirmed influenza, toxoplasmosis and varicella had amoxicillin switched to oseltamivir, cotrimoxazole or valaciclovir. 46/77 patients diagnosed with bacterial, influenza virus or TORCH infection required management or follow-up changes $(60 \%)$. Outcome — One mother with meningo-encephalitis required ICU management and then fully recovered. Data on delivery were available in 98 cases: 11 prematurely (median 35 WG [33.5-36]), including 2 with fetal losses at the moment of fever (at $21 \mathrm{WG}$ in the context of lobar pneumonia and at $32 \mathrm{WG}$ in unexplained fever). Infants showed no sign of infection.

\section{Discussion}

116 In this multicentric prospective study, we analyzed the causes of fever in pregnant women with undifferentiated fever in whom anti-Listeria preemptive therapy was prescribed. A diagnosis was made in $75 \%$, with viral infections accounting for most cases, etiologies varied according to seasons and $60 \%$

119 of cases with a diagnosis required management/follow-up changes. Infections exhibit non-specific and 120 sometimes misleading presentation in pregnancy [2]. In this study, most patients with confirmed 121 influenza had elevated CRP rates. This underlines the need for repeated evaluations, as specific 122 symptoms may appear and help identify the cause of fever.

124 Twenty-six patients (23\%) with undifferentiated fever had no final diagnosis but good evolution under 125 anti-Listeria therapy. They actually may have had maternal listeriosis despite negative cultures, as blood 126 cultures are reported negative in $45 \%$ of maternal listeriosis[4]. Indeed, they all reported food exposure 127 and exhibited inflammatory blood parameters compatible with bacterial infections. Administration of 128 anti-Listeria therapy for undifferentiated fever during pregnancy could prevent the development of 129 microbiologically proven maternal-neonatal listeriosis, and account, on top of food prevention measures, for the sharp decline in maternal-fetal listeriosis [12]. 
131 A limitation of this study is its observational nature. However it shows that undifferentiated fever in

132 pregnant women reflects a large array of benign to potentially severe infections, and may warrant 133 preemptive anti-Listeria treatment together with careful repeated evaluation.

134 
135 Table 1. Features of the 103 pregnant women with acute undifferentiated fever

\begin{tabular}{|c|c|}
\hline Parameter & $\mathbf{N}=*$ \\
\hline \multicolumn{2}{|l|}{ Epidemiological features } \\
\hline Median age [Q1; Q3] & 32 [29-35] \\
\hline Median gestity [Q1; Q3] and parity (range) & $2[1-3] ; 1[1-1]$ \\
\hline Twin pregnancy $n=(\%)$ & $6 / 103(5 \%)$ \\
\hline Median term at the moment of infection (weeks of gestation) [Q1; Q3] & $32[28-36]$ \\
\hline \multicolumn{2}{|l|}{ Geographical origin } \\
\hline France & $45 / 103(44 \%)$ \\
\hline Europe & $10 / 103(10 \%)$ \\
\hline Maghreb & $22 / 103(21 \%)$ \\
\hline Sub-Saharan Africa & $22 / 103(21 \%)$ \\
\hline Other & $4 / 103(4 \%)$ \\
\hline At least one immunosuppressing comorbidity & $10 / 103(10 \%)$ \\
\hline HIV infection ${ }^{\dagger}$ & $4 / 103(4 \%)$ \\
\hline Auto-immune disease & $6 / 103(6 \%)$ \\
\hline Sickle cell disease & $2 / 103(2 \%)$ \\
\hline Another comorbidity & $27 / 103(26 \%)$ \\
\hline \multicolumn{2}{|l|}{ Final diagnosis } \\
\hline Bacterial infections & $22 / 103(21 \%)$ \\
\hline Pyelonephritis & $16 / 103(16 \%)$ \\
\hline Pneumonial & $3 / 103(3 \%)$ \\
\hline Periapical or dental abscess & $2 / 103(2 \%)$ \\
\hline Digestive tract salmonellosis & $1 / 103(1 \%)$ \\
\hline Viral seasonal infections & $52 / 103(50 \%)$ \\
\hline Upper respiratory tract infections** & $23 / 103(22 \%)$ \\
\hline Influenza $^{++}$ & $21 / 103(20 \%)$ \\
\hline Gastroenteritis & $6 / 103(5 \%)$ \\
\hline Viral meningitis & $2 / 103(2 \%)$ \\
\hline TORCH infections & $3 / 103(3 \%)$ \\
\hline Toxoplasmosis & $1 / 103(1 \%)$ \\
\hline Varicella & $1 / 103(1 \%)$ \\
\hline CMV primo-infection & $1 / 103(1 \%)$ \\
\hline No final diagnosis & $26 / 103(25 \%)$ \\
\hline
\end{tabular}

*The study population included the 103 pregnant women.

${ }^{+}$Mean CD4 cells count in HIV infected patients ranged from $112-870 / \mathrm{mm}^{3}$.

$\$$ Auto immune diseases were: type I diabetes $(n=2)$, multiple sclerosis $(n=2)$, Crohn diseases and erythematous systemic lupus $(n=1$, each), Of them, one patient with multiple sclerosis reported concomitant corticosteroid therapy at the moment of infection.

$\S$ Other comorbidities included: Asthma $(n=5)$, Bipolar disease and Schizophrenia $(n=2$, each), hypertension ( $n=2)$, epilepsy, Charcot-MarieTooth disease, vitiligo, narcolepsy, chronic hepatitis B $(n=1$, each). Each patient reported 0 to 3 comorbidities.

"Among the 16 patients with pyelonephritis, only 6 reported minor pain when urinating or pollakiuria. Ultrasound evaluation documented pyelitis in 4 cases, and acute ureteral obstruction in 3 cases. Bacteriological documentation was available in 9 cases and included amoxicillin resistant Escherichia coli $(\mathrm{n}=6)$, Klebsiella pneumoniae $(\mathrm{n}=2)$ and Streptococcus agalactiae $(\mathrm{n}=1)$.

"Chest $\mathrm{x}$-ray was performed in each case and evidenced focal consolidation area $(\mathrm{n}=2)$ or alveolo-interstitial infiltrate $(\mathrm{n}=1)$.

** Upper respiratory tract infections included pharyngitis, tracheitis or bronchitis. Patients reported contact with index case and subsequent cough and nasal discharge.

t+ Among the 21 patients with influenza, influenza A was confirmed by PCR in 14, Influenza B in 5; data was not available for 2 patients. \# TORCH infections denote a cluster of symptoms caused by congenital infection with Toxoplasma gondii, Rubella virus, Cytomegalovirus, Herpes simplex virus, and other organisms including Treponema pallidum, Parvovirus B19, and Varicella zoster virus. 
154 Funding: Programme hospitalier de recherche clinique, Institut Pasteur, Inserm, Santé Publique France

155 Conflict of Interest: none.

157 Ethical approval: In accordance with French legislation, the study received Institutional Review Board approval by an ethical committee (Comité de Protection des Personnes Ile-de-France 3, November 6th 159 2009).

Informed consent: All participants provided written informed consent.

\section{References}

1. Surgers L, Bleibtreu A, Burdet C, Clermont O, Laouenan C, Lefort A, Mentre F, Carbonne B, Bingen E, Meynard JL, Denamur E (2014) Escherichia coli bacteraemia in pregnant women is life-threatening for foetuses. Clin Microbiol Infect 20 (12):O1035-1041. doi:10.1111/1469-0691.12742

2. Le Gouez A, Benachi A, Mercier FJ (2016) Fever and pregnancy. Anaesth Crit Care Pain Med 35 Suppl 1:S5S12. doi:10.1016/j.accpm.2016.06.007

3. Mallart E, Charlier C (2018) [Main complications of pregnancy. Fever and pregnancy]. Rev Prat 68 (7):e277e282

4. Charlier C, Perrodeau E, Leclercq A, Cazenave B, Pilmis B, Henry B, Lopes A, Maury MM, Moura A, Goffinet F, Dieye HB, Thouvenot P, Ungeheuer MN, Tourdjman M, Goulet V, de Valk H, Lortholary O, Ravaud P, Lecuit M (2017) Clinical features and prognostic factors of listeriosis: the MONALISA national prospective cohort study. Lancet Infect Dis 17 (5):510-519. doi:10.1016/S1473-3099(16)30521-7

5. Mylonakis E, Paliou M, Hohmann EL, Calderwood SB, Wing EJ (2002) Listeriosis during pregnancy: a case series and review of 222 cases. Medicine 81 (4):260-269

6. Elinav H, Hershko-Klement A, Solt I, Glikman D, Nir-Paz R (2015) Pregnancy-associated listeriosis: many beliefs, few facts. Lancet Infect Dis 15 (10):1128-1130. doi:10.1016/S1473-3099(15)00302-3

7. Elinav H, Hershko-Klement A, Valinsky L, Jaffe J, Wiseman A, Shimon H, Braun E, Paitan Y, Block C, Sorek R, Nir-Paz R (2014) Pregnancy-associated listeriosis: clinical characteristics and geospatial analysis of a 10-year period in Israel. Clin Infect Dis 59 (7):953-961. doi:10.1093/cid/ciu504

8. Janakiraman V (2008) Listeriosis in pregnancy: diagnosis, treatment, and prevention. Rev Obstet Gynecol 1 (4):179-185

9. Charlier C, Goffinet F, Azria E, Leclercq A, Lecuit M (2013) Inadequate management of pregnancy-associated listeriosis: lessons from four case reports. Clin Microbiol Infect. doi:10.1111/1469-0691.12281

10. Benshushan A, Tsafrir A, Arbel R, Rahav G, Ariel I, Rojansky N (2002) Listeria infection during pregnancy: a 10 year experience. Isr Med Assoc J 4 (10):776-780

11. Committee on Obstetric Practice ACoO, Gynecologists (2014) Committee Opinion No. 614: Management of pregnant women with presumptive exposure to Listeria monocytogenes. Obstet Gynecol 124 (6):1241-1244. doi:10.1097/01.AOG.0000457501.73326.6c

12. de Valk H, Tourdjman, M., Leclercq, A., Maury, M., Moura, A., Laurent, E., Chenal-Francisque, V., Goulet, V., Brisse, S., and Lecuit, M. Changes in epidemiology and surveillance of listeriosis in France. In: International Symposium On Problems of Listeriosis., Paris, 2016. Institut Pasteur, 

Lecompte T, Elefant E, Faure K, Gauzit R, Gavazzi G, Lemaitre L, Raymond J, Senneville E, Sotto A, Subtil D, Trivalle C, Merens A, Etienne M (2018) Practice guidelines for the management of adult community-acquired urinary tract infections. Med Mal Infect 48 (5):327-358. doi:10.1016/j.medmal.2018.03.005 